\title{
Eosinophilic Esophagitis and Ige-Mediated Allergy in Children: Specific Ige by Component-Based-Allergen Microarray
}

\section{Francesca Rea ${ }^{1 *}$, Leila Emma D’Urbano ${ }^{2}$, Rosa Luciano², Marta Muraca ${ }^{3}$, Luigi Dall’Oglio', Giovanni Cavagni ${ }^{4}$ and Paola De Angelis ${ }^{1}$}

${ }^{1}$ Digestive Surgery and Endoscopy Unit, Bambino Gesù Children's Hospital- IRCCS, Rome, Italy

${ }^{2}$ Pediatric Laboratory Medicine, Bambino Gesù Children's Hospital- IRCCS, Rome, Italy

${ }^{3}$ Pediatric Immunology University "La Sapienza", School of Medicine, Rome

${ }^{4}$ Pediatric Medicine, Bambino Gesù Children's Hospital- IRCCS, Rome and European Diagnostic Center DRP, Parma, Italy

\begin{abstract}
Background: Atopy is prevalent in eosinophilic esophagitis (EoE) but the relative role of airborn and food allergens in the etiopathogenesis is still incompletely understood; allergic immediate and delayed reactions are involved.

Objective: We characterized the slgE profile by a component-based allergen microarray with highly purified allergens in EoE in comparison with traditional slgE assay and we evaluated a possible correlation between clinical features and slgE results.

Methods: In 30 consecutive patients diagnosed with EoE, three diagnostic tests were performed: skin prick test (SPT), ImmunoCAP ${ }^{\circledR}$ slgE and an allergen component microarray chip called ImmunoCAP ${ }^{\circledR}$ ISAC. The ISAC chips cover 103 recombinant or purified allergen molecules including food, airborn and cross-reactive allergens.

Results: Out of the 30 patients, 15, 16 and 17 of the patients were sensitized as assess with SPT, ISAC and ImmunoCAP ${ }^{\circledR}$ respectively. Thirteen of the patients were multi-sensitized. The three diagnostic methods were in good agreement for all patients; the ISAC method provided new information in 8 patients, not revealed by the traditional tests, either by detection of panallergens or unsuspected triggering allergens.

Conclusions: slgE detection by the ISAC microarray revealed that airborne allergens and panallergens are more frequently involved than food allergens in our population. The ISAC data were in agreement with both traditional tests and doctor's diagnosis/open challenge and revealed new information that can improve understanding of the EoE pathogenesis and management.
\end{abstract}

Key message: immune-solid phase allergen chip (ISAC) gives new information about cross reactive molecules and identification of panallergens, which are not possible to obtain from traditional test.

Keywords: Aeroallergens; Immune Solid Phase Allergen Chip (ISAC); Eosinophilic esophagitis; Food allergens; Specific IgE; ImmunoCAP

Abbreviations: EoE: Eosinophilic Esophagitis; GERD: Gastroesophageal Reflux Disease; PPI: Proton Pump Inhibitor; sIgE: Specific IgE; SPT: Skin Prick Test; ISAC: Immune Solid Phase Allergen Chip; APT: Atopy Patch Test; FCT: Food Challenge Test; HPF: High Power Field

\section{Introduction}

EoE is a chronic immuno-allergic-inflammatory disease related to multiple factors. According to Furuta et al. [1] diagnosis of EoE included clinical suspicion, $\geq 15$ eosinophils/HPF and exclusion of other diseases such as GERD. In 2011, Liacouras et al. [2] introduced "proton pump inhibitors-PPI-responsive esophageal eosinophilia" to identify patients responsive to PPI therapy [2]. Endoscopy with biopsies represents the first step in defining EoE.

Atopy with sensitization to food and aeroallergens is more prevalent in EoE than in general population, but interpretation of allergy testing need to be improved [3].

According to Spergel et al. [4], skin-prick (SPT) and patch tests may be more effective than SPT alone in identifying potential allergen triggers [4]. Serum immunoglobulin (Ig)E CAP for food allergens are more effective compared to SPT and APT[5].

Molecular diagnosis is useful to characterize the pattern of food and inhalant hypersensitivity and to underline a possible cross-reactivity between food and environmental allergens [6].

Protein microarrays have recently become available for measuring sIgE. This technology has two main advantages compared to conventional SPT and ImmunoCAP specific IgE assay: it assesses simultaneously sIgE to many recombinant or highly purified allergens and it requires small amounts of blood, an advantage in children [714].

Aim of this study was to characterize the sIgE profile with highly purified allergens (ISAC) in children with EoE, in comparison with traditional $\operatorname{sIgE}$ assay and to evaluate sensitization pattern in a paediatric population.

*Corresponding author: Francesca Rea, Digestive Surgery and Endoscopy Unit Bambino Gesù Children's Hospital, IRCCS, Piazza Sant'Onofrio 4, 00165, Rome, Italy, Tel.: 390668592841; Fax: 390668592949; E-mail: reafranci@gmail.com

Received May 12, 2013; Accepted June 18, 2014; Published June 25, 2014

Citation: Rea F, D'Urbano LE, Luciano R, Muraca M, Dall'Oglio L, et al. (2014) Eosinophilic Esophagitis and Ige-Mediated Allergy in Children: Specific Ige by Component-Based-Allergen Microarray. J Allergy Ther 5: 180. doi:10.4172/21556121.1000180

Copyright: (c) 2014 Rea F, et al. This is an open-access article distributed unde the terms of the Creative Commons Attribution License, which permits unrestricted use, distribution, and reproduction in any medium, provided the original author and source are credited. 
Citation: Rea F, D'Urbano LE, Luciano R, Muraca M, Dall'Oglio L, et al. (2014) Eosinophilic Esophagitis and Ige-Mediated Allergy in Children: Specific Ige by Component-Based-Allergen Microarray. J Allergy Ther 5: 180. doi:10.4172/2155-6121.1000180

\section{Methods}

Thirty consecutive patients (Male: 23) affected by EoE according to the criteria of Furuta et al. [1] and Liacouras et al. [2] were enrolled. All patients with clinical signs of hypersensitivity to specific substances were considered allergic, regardless of the presence of positive testing.

In all patients SPT, ImmunoCAP and ISAC microarray tests were performed. The study was approved by the Hospital Ethical Committee and an informed consent was obtained from parents before enrolment. Laboratory personnel were not informed about the results of the SPT, performed under the control of a pediatric allergist.

\section{Skin prick test}

SPT were performed with commercial natural extracts to suspected triggering food and airborne allergens for each patient. Hence, different patients were tested with different panels of suspected allergens according to the clinical history the diagnostic routine and guidelines used at the hospital. The allergens used were: foods (milk, a-lactalbumin, $\beta$-lactoglobulin, casein, egg white, egg yolk, soybean, rice, wheat, corn, beef, chicken codfish, carp, tomato, potato, peanut and hazelnut), inhalant (dust mite, timothy grass, wall pellitory, olive, cat and dog dandruff) and with sodium chloride saline $(0.9 \%)$ and histamine hydrochloride (Lofarma, Milan, Italy). The response was read 15 minutes after puncture and results expressed as the mean wheal diameter $(\mathrm{mm})$. The appearance of erythema with a diameter $>3 \mathrm{~mm}$ was defined as a positive reaction.

\section{Fluorescence enzyme immunoassays}

Similarly as for SPT, routine determination of sIgE antibodies against suspected triggering allergens were performed including milk, ( $\alpha$-lactalbumin, $\beta$-lactoglobulin, casein), egg white and egg yolk, fish, wheat, tree pollens [cypress (Cupressus Aarizonica), olive (Olea Europaea)], weed pollens [wall pellitory (Parietaria Officinalis and Parietaria Judaica)]), grass pollens [bermuda (Cynodon Dactylon), ryegrass (Lolium Perenne), timothy (Phleum pratense)], mites (dust mite (Dermatophagoides Pteronyssinus, flour mite (Dermatophagoides Farinae), molds (Aspergillus Fumigatus and Alternaria Alternata) and cat and dog dandruff was performed with a widely-used fluorescence enzyme immunoassay according to the manufacturer instruction (ImmunoCAP System ${ }^{\mathrm{TM}}$ Phadia AB, Uppsala, Sweden). sIgE titres were quantified in protein units designated as $\mathrm{kU} / \mathrm{l}$, according to the manufacturer.

\section{Allergen microarray assay}

All patients were tested with the same panel of 103 allergenic molecules. The commercially available allergen chips were purchased from Phadia AB (Uppsala, Sweden) and the assay performed according to the instruction provided by the manufacturer [13]. A customized version of the microarray (ISAC ${ }^{\mathrm{TM}}$ version CRD103) containing 103 purified or recombinant allergenic molecules was used. Chips were washed for one hour in the washing buffer, rinsed and dried. $20 \mu \mathrm{L}$ of undiluted serum was applied onto each reaction well. Chips were incubated for 2 hours at room temperature in a humid chamber, rinsed and washed twice in washing buffer and once in deionized water. Chips were incubated for 1 hour at room temperature with $20 \mu \mathrm{L}$ of an Alexa 546-labelled anti-human IgE antibody, washed, dried and stored in the dark until scanning. Scan Array Gx Scanner (Perkin-Helmer, Boston, MA) with two laser power settings was used in order to achieve a maximum dynamic range across different levels of IgE concentrations.
Images were analysed using the MIA software (Version 3.1; Phadia AB) and sIgE were quantified as ISU (ISAC Standardized Units).

\section{Results}

\section{Patient characteristics}

Patients' characteristics are summarized in Table 1. Twenty two out of 30 patients $(73 \%)$ presented a personal history of atopy with clinical signs of allergy. Respiratory symptoms were reported in $15 \mathrm{EoE}$ patients (asthma $(6 / 22,28 \%$, rhinitis $9 / 22,41 \%)$, symptoms suggestive of food allergy were present in 6 children (vomiting 4/22, oral allergy syndrome $1 / 22,5 \%$, anaphylaxis $1 / 22,5 \%$ ). Only one patient presented atopic dermatitis.

Food impaction was the onset symptom in 9 patients; the other patients presented a specific symptom of EoE at diagnosis (abdominal pain, dysphagia, heartburn, vomiting, failure to thrive). In thirteen out of 30 patients (43\%) peripheral eosinophilia was present.

\section{sIgE results}

The prevalence of the sensitization to at least one allergen was $53 \%$ (16/30 patients) with microarray, 57\% (17/30) with ImmunoCAP and $50 \%(15 / 30)$ with SPT. According to microarray results sIgE to inhalant molecules were elevated in $17 / 30(57 \%)$ patients (pollens $13 / 30,44 \%$, mite $7 / 30,24 \%$, pets $5 / 30,17 \%$, fungi $4 / 30,13 \%$ ). Further, sIgE to panallergens were found in 7/30, (LTP $6 / 30$, profilin $5 / 30$, PR-10 2/30, tropomyosin $1 / 30$ ) and sIgE to foods were distributed as follows: milk $1 / 30$, egg $1 / 30$, fish $1 / 30$, and kiwi $3 / 30$, peanut $1 / 30$. The results of allergy tests (SPTs, ImmunoCAP and microarray) are summarized in Table 2 .

\section{Comparison of microarray results with extract-based ImmunoCAP and SPT results}

For 22 out of 30 patients microarray results were in agreement with the results obtained with traditional diagnostics (Table 3).

\begin{tabular}{|c|c|}
\hline Population & Patients 30 \\
\hline Male & 23 \\
\hline Female & 7 \\
\hline Median Age (years) & $9.0-0.7(0.9-19)$ \\
\hline Food Impact at diagnosis of EE & 9 \\
\hline $\begin{array}{l}\text { Allergic symptoms } \\
\text { Respiratory symptoms: } \\
\text { Asthma } 6 \text {; rhinitis } 9 \\
\text { Food allergy symptoms: } \\
\text { vomiting } 4 \text {; oral allergy syndrome (OAS) } 1 \text {, anaphylaxis } 1 . \\
\text { Atopic dermatitis }\end{array}$ & $\begin{array}{l}22 \\
15 \\
6 \\
1\end{array}$ \\
\hline $\begin{array}{l}\text { Endoscopic features } \\
\text { linear furrow } \\
\text { white specks } \\
\text { trachealization } \\
\text { stenosis } \\
\text { aspecific esophagitis }\end{array}$ & $\begin{array}{l}11 \\
8 \\
2 \\
2 \\
7\end{array}$ \\
\hline $\begin{array}{l}\text { Histology } \\
\text { eosinophils peak count } 15-45 \\
\text { eosinophils peak count }>45\end{array}$ & $\begin{array}{l}13 \\
17\end{array}$ \\
\hline 24 h pH/impedance: negative & 17 \\
\hline 24 h pH/impedance: mild GER* & 13 \\
\hline Peripheral eosinophilia & 13 \\
\hline $\begin{array}{l}\text { Associated disease } \\
\text { coeliac disease } \\
\text { esophageal atresia repaired }\end{array}$ & $\begin{array}{l}3 \\
4\end{array}$ \\
\hline
\end{tabular}

*Mild GERD not responsive to high dosage of PPI

Table 1: Patients' characteristics, endoscopic and histological features. 
Citation: Rea F, D'Urbano LE, Luciano R, Muraca M, Dall'Oglio L, et al. (2014) Eosinophilic Esophagitis and Ige-Mediated Allergy in Children: Specific Ige by Component-Based-Allergen Microarray. J Allergy Ther 5: 180. doi:10.4172/2155-6121.1000180

Page 3 of 4

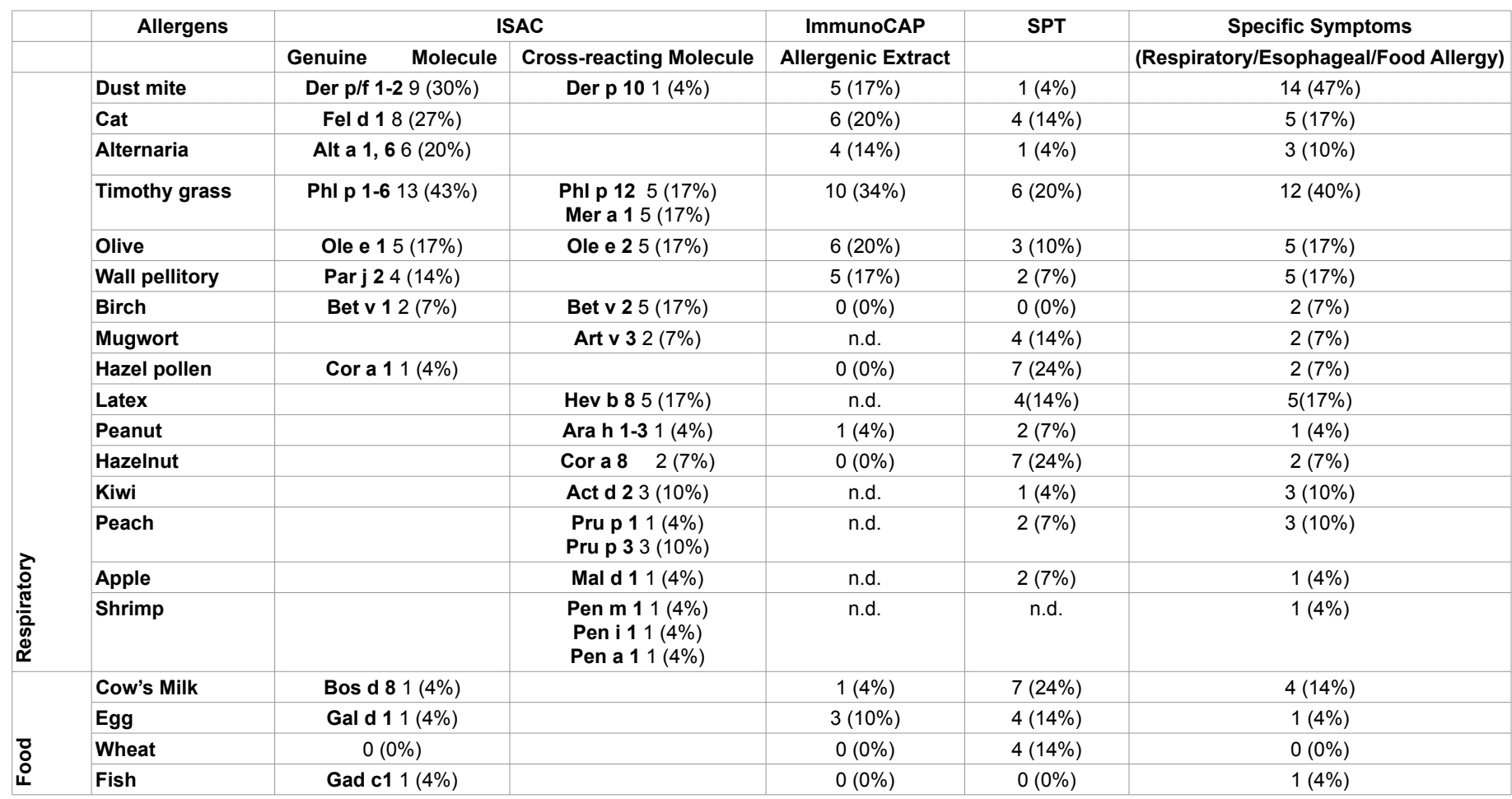

Table 2: Results of allergy testing in EoE patients $(\mathrm{N}=30)$.

\begin{tabular}{|c|c|c|c|}
\hline No. of Patients & $\begin{array}{c}\text { slgE info } \\
\text { (ImmunoCAP and/or SPT) }\end{array}$ & $\begin{array}{l}\text { slgE info } \\
\text { (ISAC) }\end{array}$ & ISAC results in agreement with clinical history \\
\hline 1 & 0 & 0 & Yes \\
\hline 2 & mite & mite & Yes \\
\hline 3 & 0 & 0 & Yes \\
\hline 5 & 0 & 0 & Yes \\
\hline 7 & 0 & 0 & Yes \\
\hline 9 & 0 (but milk SPT low pos) & 0 & Yes \\
\hline 10 & 0 & 0 & Yes \\
\hline 11 & 0 (but olive pollen SPT low positive) & 0 & Yes \\
\hline 12 & mite, mold, pollen & mite, mold, pollen & Yes \\
\hline 13 & 0 & 0 & Yes \\
\hline 14 & mite & mite & Yes \\
\hline 15 & mite, pollen & mite, pollen & Yes \\
\hline 16 & 0 & 0 & Yes \\
\hline 17 & 0 & 0 & Yes \\
\hline 19 & mold, pollen, cat & mold, pollen, cat & Yes \\
\hline 22 & 0 & 0 & Yes \\
\hline 23 & 0 & 0 & Yes \\
\hline 24 & 0 & 0 & Yes \\
\hline 25 & cat & cat & Yes \\
\hline 26 & pollen & pollen & Yes \\
\hline 27 & 0 & 0 & Yes \\
\hline 28 & mite, mold, pollen, cat & mite, mold, pollen, cat & Yes \\
\hline
\end{tabular}

Table 3: Patients with traditional tests in agreement with microarray test.

Any clinically "false" positive results on ISAC were not observed. Neither did ISAC miss any allergy-provoking allergens according to doctor's diagnosis and open challenge test.

In 5 out of 30 patients milk was detected low positive on ImmunoCAP $(1.5,1.7,1.9,2.0$ and $2.8 \mathrm{kU} / 1$ respectively), and tested negative on ISAC. These patients did not show any symptoms upon open challenge for milk.

\section{New information provided by microarray test}

For 8 out of 30 patients ISAC gave new, relevant diagnostic information which were not possible to obtain from the traditional tests (SPT or ImmunoCAP). The new information was either detection of cross-reactive molecules or identification of unsuspected allergens (Table 4). 
Citation: Rea F, D'Urbano LE, Luciano R, Muraca M, Dall'Oglio L, et al. (2014) Eosinophilic Esophagitis and Ige-Mediated Allergy in Children: Specific Ige by Component-Based-Allergen Microarray. J Allergy Ther 5: 180. doi:10.4172/2155-6121.1000180

Page 4 of 4

\begin{tabular}{|c|c|c|c|}
\hline $\begin{array}{l}\text { No. of } \\
\text { Patients }\end{array}$ & $\begin{array}{l}\text { slgE info } \\
\text { (ImmunoCAP and/or SPT) }\end{array}$ & $\begin{array}{l}\text { slgE info } \\
\text { ISAC microarray (new info in Italic) }\end{array}$ & $\begin{array}{l}\text { ISAC results in agreement } \\
\text { with clinical history }\end{array}$ \\
\hline 4 & mite, mold, cat, pollen & LTP, profilin, mite, mold, cat, pollen & Yes \\
\hline 6 & pollen & profilin, pollen & Yes \\
\hline 8 & pollen & peanut (Ara $h 1$ and 2), LTP, Pollen & Yes \\
\hline 18 & mold, pollen mite & $\begin{array}{l}\text { LTP, tropomyosin, profilin, mite, mold, } \\
\text { pollen,cat }\end{array}$ & Yes \\
\hline 20 & pollen, cat & fish, pollen, cat & Yes \\
\hline 21 & pollen, cat & PR-10, pollen, cat & Yes \\
\hline 29 & $\begin{array}{l}\text { many foods from plant origin e.g. peanut (3.9), walnut (1.4) hazelnut (9.8), } \\
\text { tomato (1.8), apple (50) peach (24). Dust mite, mold, pollen not tested. }\end{array}$ & LTP, profilin, mite, mold, pollen & Yes \\
\hline 30 & Milk, soy. Dust mite, mold, pets not tested. & profilin, mite, pollen, cat, mouse & Yes \\
\hline
\end{tabular}

Table 4: Patients where the microarray test gave more information compared to traditional tests.

Thirteen out of the 16 patients tested positive with ISAC were multi-sensitized (i.e. sensitized to 3 or more different types of allergens, e.g. grass, mite and mold or 3 different pollen species like birch, olive and grass).

\section{Discussion}

In our study, we limited evaluations to immediate allergic reactions. The high reported prevalence of respiratory allergy, commonly linked to immediate processes, is confirmed in our experience. A previous study on 76 adults using ISAC (112 allergens) demonstrated that $74 \%$ of patients had aeroallergens sensitization and that birch pollen sensitization ( $\mathrm{r}$ Bet $\mathrm{v} 1$ ) had cross reaction with some food allergens [15]. This study showed that patients had poly-sensitization to food and aeroallergens and allergens identified will be useful to direct dietary therapy.

A good correlation between the measurement of sIgE with allergen microarray and the clinical signs was found for inhalant molecules (dust mite and birch), panallergens (latex, kiwi) and food (fish). The number of positive allergens identified with ISAC was higher than ImmunoCAP. The high sensitivity of sIgE detection with ISAC improved identification of sensitized patients amenable to appropriate prophylaxis and possible specific therapy. Thirteen of 16 patients tested positive with ISAC were multi-sensitized (i.e. sensitized to 3 or more different types of allergens, e.g. grass, mite and mold or 3 different pollen species like birch, olive and grass).

For $8 / 30$ patients ISAC gave new, relevant diagnostic information, not obtained before with traditional tests (SPT or ImmunoCAP): panallergens, molecules cross-reacting with the more common allergens. The panallergens encompasses families of related proteins, involved in general vital processes and thus, widely distributed throughout nature. They are responsible for many IgE cross-reactions even between unrelated pollen and plant food allergen source. Although usually considered as minor allergens, sensitization to panallergens might be problematic as it bears the risk of developing multiple sensitizations.

In this study only 8 patients had food hypersensitivity; we couldn't identify non-IgE-mediated food reaction. Therefore it is essential in a future study use a test for the determination of non-IgE mediated reactions in the EoE patients.

In our population, microarrays are in agreement with ImmunoCAP and SPT. Also, ISAC didn't miss any allergens related to patients' symptoms. In addition, the microarray allows a targeted therapy: seasonal anti-inflammatory treatment, specific immunotherapy and dietary restriction based on the identification of cross-reacting molecules. The quality of the microarray is good enough compared to traditional diagnostic tests, open challenge test and clinical diagnosis.

\section{Acknowledgement}

Annica Önell for scientific support.

\section{References}

1. Furuta GT, Liacouras CA, Collins MH, Gupta SK, Justinich C, et al. (2007) Eosinophilic esophagitis in children and adults: a systematic review and consensus recommendations for diagnosis and treatment. Gastroenterology 133: $1342-1363$

2. Liacouras CA, Furuta GT, Hirano I, Atkins D, Attwood SE, et al. (2011) Eosinophilic esophagitis: updated consensus recommendations for children and adults. J Allergy Clin Immunol 128: 3-20.

3. Assa'ad A (2008) Eosinophilic esophagitis: association with allergic disorders Gastrointest Endosc Clin N Am 18: 119-132.

4. Spergel JM, Beausoleil JL, Mascarenhas M, Liacouras CA (2002) The use of skin prick tests and patch tests to identify causative foods in eosinophilic esophagitis. J Allergy Clin Immunol 109: 363-368.

5. Erwin EA, James HR, Gutekunst HM, Russo JM, Kelleher KJ, et al. (2010) Serum IgE measurement and detection of food allergy in pediatric patients with eosinophilic esophagitis. Ann Allergy Asthma Immunol 104: 496-502.

6. Straumann A, Aceves SS, Blanchard C, Collins MH, Furuta GT, et al. (2012) Pediatric and adult eosinophilic esophagitis: similarities and differences. Allergy 67: 477-490.

7. Harwanegg C, Laffer S, Hiller R, Mueller MW, Kraft D, et al. (2003) Microarrayed recombinant allergens for diagnosis of allergy. Clin Exp Allergy 33: 7-13.

8. Harwanegg C, Hiller R (2004) Protein microarrays in diagnosing IgE-mediated diseases: spotting allergy at the molecular level. Expert Rev Mol Diagn 4: 539548.

9. Harwanegg C, Hiller R (2005) Protein microarrays for the diagnosis of allergic diseases: state-of-the-art and future development. Clin Chem Lab Med 43 1321-1326.

10. Poulsen LK, Pedersen MH, Dufva M (2007) Allergology on a chip. Clin Exp Allergy 37: 1736-1737

11. Gaudin JC, Rabesona H, Choiset Y, Yeretssian G, Chobert JM, et al. (2008) Assessment of the immunoglobulin E-mediated immune response to milkspecific proteins in allergic patients using microarrays. Clin Exp Allergy 38 686-693.

12. Deinhofer K, Sevcik H, Balic N, Harwanegg C, Hiller R, et al. (2004) Microarrayed allergens for IgE profiling. Methods 32: 249-254.

13. Wöhrl S, Vigl K, Zehetmayer S, Hiller R, Jarisch R, et al. (2006) The performance of a component-based allergen-microarray in clinical practice. Allergy 61: 633-639.

14. D'Urbano LE, Pellegrino K, Artesani MC, Donnanno S, Luciano R, et al. (2010) Performance of a component-based allergen-microarray in the diagnosis of cow's milk and hen's egg allergy. Clin Exp Allergy 40: 1561-1570.

15. van Rhijn $B D$, van Ree $R$, Versteeg $S A$, Vlieg-Boerstra BJ, Sprikkelman $A B$ et al. (2013) Birch pollen sensitization with cross-reactivity to food allergens predominates in adults with eosinophilic esophagitis. Allergy 68: 1475-1481. 